\title{
Health related quality of life and psychological wellbeing in patients with hypertrophic cardiomyopathy
}

\author{
Steven Cox, Ann C O’Donoghue, William J McKenna, Andrew Steptoe
}

\begin{abstract}
Objective-To assess the health related quality of life and psychological wellbeing of patients with hypertrophic cardiomyopathy, to correlate these with symptoms, clinical, and psychosocial factors.

Design-Questionnaire distributed to 171 hypertrophic cardiomyopathy patients aged at least 14 years, selected at random from a dataset of $\mathbf{4 8 0}$ patients. Assessments included the Short Form 36 (SF36) Health Survey, the Hospital Anxiety and Depression questionnaire, and measures of adjustment, worry, and patient satisfaction.
\end{abstract}

Results-There was an $80.1 \%$ response rate to the questionnaire. Patients had severe limitations in all eight dimensions of quality of life assessed by the SF-36: physical functioning, role limitations owing to physical problems, role limitations owing to emotional problems, social functioning, mental health, general health perceptions, vitality, and bodily pain. Levels of anxiety and depression were also high compared with population norms. Quality of life was particularly impaired in patients with chest pain and dyspnoea, but was less consistently related to clinical cardiological measures. Adjustment to the condition and patient satisfaction were generally good. In multivariate analysis, quality of life was associated with a combination of symptom patterns and psychosocial factors. No differences in quality of life, anxiety or depression were observed between patients with no known family history, those with familial cardiomyopathy, and patients with a family history of premature sudden death. Conclusions-Hypertrophic cardiomyopathy is associated with substantial restrictions in health related quality of life. Symptoms, adjustment, and quality of interactions with clinical staff contribute to these limitations. Recognition of the problems confronted by patients with hypertrophic cardiomyopathy requires continued efforts at education both of the public and health professionals.

(Heart 1997;78:182-187)

Keywords: hypertrophic cardiomyopathy; quality of life; patient satisfaction
Hypertrophic cardiomyopathy is a chronic condition with extensive emotional and social ramifications. Patients are confronted with a potentially life threatening problem, and may perceive their levels of physical activity severely curtailed. Hypertrophic cardiomyopathy is familial in a substantial proportion of cases, ${ }^{1}$ giving rise to fear of transmission and issues surrounding genetic counselling. Many patients are diagnosed following a sudden death in the family, so may be suffering the pain of bereavement while attempting to come to terms with their own health risk. The impact of diagnosis is likely, therefore, to extend beyond the immediate symptoms and limitations of the condition. To our knowledge, there has been no systematic evaluation of health related quality of life in patients with hypertrophic cardiomyopathy. The present study assessed quality of life using a well established multidimensional measure, together with assessments of psychological wellbeing, adjustment, and other factors. The primary aim was to study the level of health related quality of life and psychological wellbeing among hypertrophic cardiomyopathy patients compared with the general population and with patients with other serious cardiac problems. The second aim was to identify the clinical, demographic, and psychosocial factors that predict limitations in quality of life in patients with hypertrophic cardiomyopathy.

\section{Patients and methods}

One hundred and seventy one patients were selected at random using a computer program from the 480 patients with hypertrophic cardiomyopathy aged at least 14 years who are part of the dataset at St George's Hospital in London. Hypertrophic cardiomyopathy was defined by characteristic clinical, echocardiographic, and haemodynamic features. ${ }^{2}$ Each patient was sent an explanatory letter, a set of questionnaires, and a reply paid envelope. Complete data were returned by $137(80 \cdot 1 \%)$ and incomplete data by $12(6.4 \%) ; 23$ $(13.5 \%)$ patients failed to respond. For the purposes of analysis, patients were divided into three groups according to family history, separating patients with no known cardiomyopathy in their families $(n=62)$, those with familial cardiomyopathy $(n=32)$, and patients with a family history of one or more premature sudden deaths $(n=43)$. 


\section{MEASURES}

Quality of life

Quality of life was assessed using the Short Form 36 Health Survey (SF-36), a multidimensional measure developed by the Rand Corporation in the Medical Outcomes Study. ${ }^{3}$ This measure has been widely used in quality of life studies, and normative data for the UK have been published. ${ }^{4}$ The measure assesses eight dimensions of functioning: physical functioning, role limitations owing to physical problems, role limitations owing to emotional problems, social functioning, mental health, general health perceptions, vitality or energy, and bodily pain. Scores were coded and transformed to a scale where $0=$ worst possible health and $100=$ best possible health.

\section{Psychological wellbeing}

Anxiety and depression were assessed with the Hospital Anxiety and Depression scale, a 14 item questionnaire designed to assess emotional distress with items uncontaminated by the somatic symptoms associated with medical disorders. ${ }^{5}$ The questions address the patients' emotion over the past week, for example "I feel cheerful" (depression item, reverse scored) and "worrying thoughts go through my mind" (anxiety), each of which is rated on a four point scale. Scores can range from 0-21, with higher scores reflecting greater degrees of anxiety and depression. Scores of eight or more are suggestive of borderline emotional disorder, while 11 or more is indicative of probable emotional disorder.

\section{Adjustment and worry about hypertrophic cardiomyopathy}

Patients' experience of hypertrophic cardiomyopathy was measured with a questionnaire derived from the Cancer Adjustment Inventory designed by Berrenberg ${ }^{6}$ and other sources. Each statement was rated on a five point scale from "strongly agree" to "strongly disagree". Factor analysis with varimax rotation identified three orthogonal factors that together accounted for $55.4 \%$ of the variance. The first scale was labelled in adjustment to hypertrophic cardiomyopathy and consisted of five items including "a person with cardiomyopathy can lead a fully satisfying life" and "I have a difficult time adjusting to the limitations of my condition" (reverse scored). This scale had high internal consistency (Cronbach $\alpha=0.81$ ), and total scores could range from 5-25. Subsequently patients were divided into those with poor $(\leqslant 10)$, moderate (11-19), and good $(\geqslant 20)$ adjustment. The second factor, worry about hypertrophic cardiomyopathy, included three items, $(\alpha=0.71)$ such as "the genetic aspects of cardiomyopathy worry me" (reverse scored). Patients were classified into those with low $(\geqslant 12)$, moderate $(7-11)$ and high $(\leqslant 6)$ worry. The third factor reflected involvement in management, and comprised three items such as "I am taking an active role in my treatment" (Cronbach $\alpha=0.85$ ). Patients were divided into those with low $(\leqslant 6)$, moderate $(7-11)$, and high $(\geqslant 12)$ involvement in management.

\section{Patient satisfaction}

Satisfaction with clinical relationships was assessed with a specially constructed inventory, as existing measures do not adequately cover general relationships and trust together with aspects related to effective genetic counselling. The measure included 11 items such as "I felt I could express all my worries" and "the doctor was sensitive to my feelings", each rated on a five point scale. The items all loaded on a single factor and composed a scale with high internal consistency (Cronbach $\alpha=$ 0.92). Total scores could range from a minimum of 11 to a maximum of 55. Patients were divided into those with low or moderate satisfaction ( $\leqslant 33$ ), high satisfaction (34-43), and very high satisfaction $(\geqslant 44)$. Satisfaction with information was assessed with four items (Cronbach $\alpha=0 \cdot 76$ ) such as "I was provided with all the information I wished for", and "I was able to understand all the information that was presented to me". Satisfaction with time spent with clinicians was assessed with two items, "I would like to have spent more time with these staff" and "I would have liked to ask the doctor more questions" (Cronbach $\alpha$ $=0.67$ ). The overall satisfaction with clinical relationships correlated with satisfaction with information $(r=0.65, \mathrm{P}<0.001)$ and with satisfaction with time spent $(r=0.41, \mathrm{P}<$ 0.001 ), indicating a strong cluster of these experiences.

\section{Clinical data}

Information concerning symptoms was obtained by clinicians during interview, and included a history of syncope and dyspnoea classified according to New York Heart Association criteria into classes I, II, and III. A history of chest pain was classified into typical exertional angina or atypical chest pain (pain at rest of more than 30 minutes duration without evidence of infarction). Maximum left ventricular wall thickness was assessed using cross sectional and $M$ mode echocardiography. ${ }^{7}$ Maximal oxygen ventilatory capacity $\left(\mathrm{VO}_{2} \mathrm{max}\right)$, measured during maximal exercise treadmill testing (Bruce protocol), was expressed as a percentage of age, size, and sex predicted values. ${ }^{8}$ Patients were managed according to an established symptomatic and prognostic treatment algorithm. In brief, patients with dyspnoea and/or chest pain received $\beta$ blockers or verapamil; those with symptoms and a left ventricular outflow tract gradient received disopyramide, a DDD pacemaker or myectomy; those with symptomatic arrhythmias received low dose amiodarone; and those with two or more risk factors for sudden death received amiodarone or an implantable cardioverter defibrillator.

\section{Results}

The characteristics of patients in the three family history groups are summarised in table 1. Overall, $53.7 \%$ of respondents were male and $46.3 \%$ were female, but proportions did not vary across family history groups. Significant differences were seen in age $(P<$ 
Table 1 Characteristics of the three patient groups

\begin{tabular}{|c|c|c|c|}
\hline & $\begin{array}{l}\text { No family history } \\
(n=62)\end{array}$ & $\begin{array}{l}\text { Familial } \\
\text { cardiomyopathy } \\
(n=32)\end{array}$ & $\begin{array}{l}\text { Family history } \\
\text { of premature } \\
\text { sudden death } \\
(n=43)\end{array}$ \\
\hline $\begin{array}{l}\text { Sex (male:female) } \\
\text { Age (mean (SD) years) }\end{array}$ & $\begin{array}{l}35: 27 \\
47 \cdot 5(15 \cdot 8)\end{array}$ & $\begin{array}{l}16: 16 \\
41 \cdot 3(15 \cdot 5)\end{array}$ & $\begin{array}{l}23: 20 \\
38 \cdot 4(11 \cdot 9)\end{array}$ \\
\hline \multicolumn{4}{|l|}{ Marital status } \\
\hline Single & $14 \cdot 8 \%$ & $24 \cdot 1 \%$ & $17 \cdot 1 \%$ \\
\hline Married & $75 \cdot 9 \%$ & $55 \cdot 2 \%$ & $78 \cdot 0 \%$ \\
\hline Divorced/widowed & $9 \cdot 3 \%$ & $20 \cdot 7 \%$ & $4.9 \%$ \\
\hline Children & $75 \cdot 5 \%$ & $72 \cdot 4 \%$ & $65 \cdot 9 \%$ \\
\hline \multicolumn{4}{|l|}{ Identification } \\
\hline Symptoms & $35 \cdot 8 \%$ & $44 \cdot 8 \%$ & $22 \cdot 0 \%$ \\
\hline Family history & $0 \%$ & $37 \cdot 9 \%$ & $53 \cdot 7 \%$ \\
\hline Other & $64 \cdot 2 \%$ & $17 \cdot 2 \%$ & $24 \cdot 4 \%$ \\
\hline Interval since diagnosis (years) & $8 \cdot 25(6 \cdot 5)$ & $10.9(6.9)$ & $10 \cdot 0(7 \cdot 9)$ \\
\hline \multicolumn{4}{|l|}{ Dyspnoea } \\
\hline None & $52 \cdot 8 \%$ & $52 \cdot 0 \%$ & $56 \cdot 7 \%$ \\
\hline Class II & $39 \cdot 6 \%$ & $\mathbf{4 4} \cdot 0 \%$ & $40.0 \%$ \\
\hline Class III & $7 \cdot 5 \%$ & $4.0 \%$ & $3 \cdot 3 \%$ \\
\hline \multicolumn{4}{|l|}{ Chest pain } \\
\hline None & $54 \cdot 7 \%$ & $53 \cdot 8 \%$ & $64 \cdot 5 \%$ \\
\hline Atypical & $11 \cdot 3 \%$ & $23 \cdot 1 \%$ & $9 \cdot 7 \%$ \\
\hline Exertional & $20 \cdot 8 \%$ & $19 \cdot 2 \%$ & $19 \cdot 4 \%$ \\
\hline Atypical + exertional & $13 \cdot 2 \%$ & $3 \cdot 8 \%$ & $6 \cdot 5 \%$ \\
\hline \multirow{4}{*}{$\begin{array}{l}\text { Maximum left ventricular } \\
\text { wall thickness (mean (SD) mm) } \\
\mathrm{VO}_{2} \max (\text { mean }(\mathrm{SD}) \text { predicted) } \\
\text { Syncope/presyncopal symptoms }\end{array}$} & & & \\
\hline & $21 \cdot 0(5 \cdot 5)$ & $20 \cdot 9(8 \cdot 3)$ & $19 \cdot 4(5 \cdot 2)$ \\
\hline & $68 \cdot 3(15 \cdot 1)$ & $67 \cdot 8(20 \cdot 4)$ & $76 \cdot 7(45 \cdot 6)$ \\
\hline & $37 \cdot 7 \%$ & $41 \cdot 9 \%$ & $39 \cdot 0 \%$ \\
\hline
\end{tabular}

0.01 ) as patients with no family history were older on average than those with familial cardiomyopathy. Age was therefore entered as a covariate in subsequent analyses. The family history groups did not differ significantly in marital status, children, or the period of time since diagnosis. Overall, $40 \cdot 7 \%$ patients had NYHA class II and $5.6 \%$ class III dyspnoea, and these proportions did not differ with family history. For the purposes of analysis, class II and III were combined.

Exertional chest pain was experienced by $20.0 \%$ of patients, atypical pain by $13.6 \%$, and both atypical and exertional by $9 \cdot 1 \%$. Maximum left ventricular wall thickness was a mean (SD) of $20.5(6.2) \mathrm{mm}$, while $\mathrm{VO}_{2} \max$ was moderately restricted $(70.6 \%$ of predicted values). These factors did not differ between family history groups. The way in which hypertrophic cardiomyopathy was identified in the three groups differed as expected $(P<$ 0.0001 ), as patients without family histories were predominantly identified through symptoms or other routes such as routine medicals. Patients with familial cardiomyopathy were more likely to have been diagnosed through family membership.

QUALITY OF LIFE

Scores on the eight dimensions of the SF-36 are summarised in table 2 . There were no sig- nificant differences between the three family history groups on any dimension. For comparison purposes, two other sets of data are shown. The right hand column of table 2 summarises scores obtained in the Oxford Healthy Life Survey, a postal survey of randomly selected adults aged 18-64 years. ${ }^{9}$ Patients with hypertrophic cardiomyopathy had significant impairments on all eight scales of the SF36 ( $P<0.0001)$. The second comparison is with 144 patients with serious cardiac conditions included in the Medical Outcomes Study. ${ }^{10}$ They included patients with congestive heart failure reporting oedema, orthopnoea or dyspnoea on exertion, survivors of acute myocardial infarction with severe angina and/or severe symptoms of congestive heart failure, hypertensive patients with severe congestive heart failure symptoms and/or a history of stroke, and diabetic patients with complications such as previous infarction, regular angina, and severe autonomic neuropathy. There were no significant differences between hypertrophic cardiomyopathy patients and this group in terms of physical functioning, role limitations owing to physical problems, general health perceptions, vitality or bodily pain, as both sets of patients were severely impaired in these respects. However, cardiomyopathy patients reported significantly poorer quality of life in terms of role limitations owing to emotional problems, social functioning, and mental health $(P<0.01)$. This suggests that the poor quality of life of patients with hypertrophic cardiomyopathy is more general in nature than the impairments experienced by other cardiac patients.

\section{PSYCHOLOGICAL WELLBEING}

Ratings on the Hospital Anxiety and Depression scale averaged $8 \cdot 23(4 \cdot 3)$ on the anxiety subscale and $5.29(3.6)$ on the depression subscale. There were no differences between family history groups. These levels are high, considering that the cut off point for a possible case of emotional disorder is 8 . On the Hospital Anxiety and Depression anxiety subscale, $21 \cdot 2 \%$ of patients were classified as possible and $28.5 \%$ as probable cases, while on the depression subscale the values were $13 \cdot 1 \%$ and $9 \cdot 5 \%$, respectively. By way of comparison, a survey of more than 500 patients with cancer assessed at the time of initial diagnosis or first relapse identified $27 \%$ with possible or probable anxiety problems, and $8.7 \%$ with possible or probable depression. ${ }^{11}$

Table 2 Quality of life in patients with hypertrophic cardiomyopathy

\begin{tabular}{|c|c|c|c|c|c|c|}
\hline & $\begin{array}{l}\text { No family } \\
\text { history } \\
(n=62)\end{array}$ & $\begin{array}{l}\text { Familial } \\
\text { cardiomyopathy } \\
(n=32)\end{array}$ & $\begin{array}{l}\text { Family history } \\
\text { of premature } \\
\text { sudden death } \\
(n=43)\end{array}$ & $\begin{array}{l}\text { All hypertrophic } \\
\text { cardiomyopathy } \\
(n=137)\end{array}$ & $\begin{array}{l}\text { Serious cardiac } \\
\text { conditions (MOS) } \\
(n=144)\end{array}$ & $\begin{array}{l}\text { UK general } \\
\text { population (OHLS) } \\
(n=8883-9219)\end{array}$ \\
\hline $\begin{array}{l}\text { Physical functioning } \\
\text { Physical role limitations } \\
\text { Emotional role limitations } \\
\text { Social functioning } \\
\text { Mental wellbeing } \\
\text { General health perceptions } \\
\text { Vitality } \\
\text { Bodily pain }\end{array}$ & $\begin{array}{l}58 \cdot 3(23 \cdot 5) \\
54 \cdot 0(42 \cdot 8) \\
67 \cdot 7(40 \cdot 5) \\
72 \cdot 7(24 \cdot 2) \\
68 \cdot 8(19 \cdot 8) \\
49 \cdot 1(23 \cdot 3) \\
44 \cdot 8(22 \cdot 5) \\
64 \cdot 2(26 \cdot 8)\end{array}$ & $\begin{array}{l}60.2(29 \cdot 4) \\
57 \cdot 0(44 \cdot 6) \\
59 \cdot 4(43 \cdot 8) \\
69 \cdot 1(29 \cdot 8) \\
61.5(23 \cdot 8) \\
43 \cdot 4(26.0) \\
42.0(25 \cdot 9) \\
67.7(29 \cdot 2)\end{array}$ & $\begin{array}{l}65 \cdot 3(24 \cdot 7) \\
57 \cdot 7(42 \cdot 9) \\
62 \cdot 7(39 \cdot 1) \\
67 \cdot 3(26 \cdot 7) \\
63 \cdot 8(20 \cdot 9) \\
47 \cdot 4(25 \cdot 1) \\
43 \cdot 0(25 \cdot 6) \\
67 \cdot 7(26 \cdot 8)\end{array}$ & $\begin{array}{l}60.9(25 \cdot 3)^{\star} \\
55 \cdot 9(42 \cdot 9)^{\star} \dagger \\
64 \cdot 2(40 \cdot 7)^{\star} \dagger \\
70 \cdot 2(26 \cdot 3)^{\star} \dagger \\
65 \cdot 6(21 \cdot 2)^{\star} \dagger \\
47 \cdot 2(24 \cdot 4)^{\star} \\
43 \cdot 6(24 \cdot 2)^{\star} \\
66 \cdot 1(27 \cdot 2)^{\star}\end{array}$ & $\begin{array}{l}57 \cdot 4(28 \cdot 1) \\
43 \cdot 9(39 \cdot 7) \dagger \\
76 \cdot 2(37 \cdot 3) \dagger \\
80 \cdot 0(24 \cdot 4) \dagger \\
77 \cdot 6(15 \cdot 8) \dagger \\
49 \cdot 1(21 \cdot 6) \\
47 \cdot 8(21 \cdot 8) \\
65 \cdot 1(24 \cdot 7)\end{array}$ & $\begin{array}{l}88.4(18.0)^{\star} \\
85.8(29.9)^{\star} \\
82.9(31 \cdot 8)^{\star} \\
88.0(19 \cdot 6)^{\star} \\
73.8(17 \cdot 2)^{\star} \\
73.5(19 \cdot 9)^{\star} \\
61.1(19 \cdot 7)^{\star} \\
81.5(21 \cdot 7)^{\star}\end{array}$ \\
\hline
\end{tabular}

Values are means (SD)

*Significant difference between cardiomyopathy and patients with serious cardiac conditions in Medical Outcomes Study (MOS), P < 0.01

tSignificant difference between cardiomyopathy and UK general population in Oxford Healthy Life Survey (OHLS), P $<0.0001$. 
Table 3 Adjustment and patient satisfaction

\begin{tabular}{lc}
\hline & $\begin{array}{l}\text { Percentage of patients (95\% confidence } \\
\text { intervals) }\end{array}$ \\
\hline Adjustment to hypertrophic cardiomyopathy & $33 \cdot 1(25 \cdot 2-41 \cdot 0)$ \\
Good & $57 \cdot 4(49 \cdot 0-65 \cdot 7)$ \\
Moderate & $9 \cdot 6(5 \cdot 2-15 \cdot 8)$ \\
Poor & $16 \cdot 1(9 \cdot 9-22 \cdot 2)$ \\
Worry about hypertrophic cardiomyopathy & $44 \cdot 5(36 \cdot 2-52 \cdot 8)$ \\
Low & $39 \cdot 4(31 \cdot 2-47 \cdot 6)$ \\
Moderate & $59 \cdot 3(51 \cdot 0-67 \cdot 5)$ \\
High & $36 \cdot 3(28 \cdot 2-44 \cdot 4)$ \\
Active involvement in management & $4 \cdot 4(1 \cdot 7-9 \cdot 4)$ \\
High & $49 \cdot 6(41 \cdot 3-58 \cdot 0)$ \\
Moderate & $43 \cdot 1(34 \cdot 8-51 \cdot 4)$ \\
Low & $7 \cdot 3(3 \cdot 6-13 \cdot 0)$ \\
Satisfaction with clinical relationships & $51 \cdot 1(42 \cdot 7-59 \cdot 5)$ \\
Very high & $46 \cdot 0(37 \cdot 6-54 \cdot 3)$ \\
High & $2 \cdot 9(0 \cdot 8-7 \cdot 3)$ \\
Moderate/low & $37 \cdot 2(29 \cdot 1-45 \cdot 3)$ \\
Satisfaction with information & $46 \cdot 0(37 \cdot 6-54 \cdot 3)$ \\
Very satisfied & $16 \cdot 8(10 \cdot 5-23 \cdot 0)$ \\
Moderately satisfied & \\
Dissatisfied & \\
Satisfaction with time spent with clinical staff & \\
Very satisfied & \\
Moderately satisfied & Dissatisfied
\end{tabular}

Table 4 Quality of life and dyspnoea

\begin{tabular}{|c|c|c|c|}
\hline & $\begin{array}{l}\text { Dyspnoea } \\
\text { (class II or III) }\end{array}$ & No dyspnoea & $P$ \\
\hline $\begin{array}{l}\text { Physical functioning } \\
\text { Physical role limitations } \\
\text { Emotional role limitations } \\
\text { Social functioning } \\
\text { Mental wellbeing } \\
\text { General health perceptions } \\
\text { Vitality } \\
\text { Bodily pain }\end{array}$ & $\begin{array}{l}48 \cdot 3(21 \cdot 2) \\
45 \cdot 4(41 \cdot 2) \\
62 \cdot 6(41 \cdot 2) \\
66 \cdot 0(23 \cdot 9) \\
65 \cdot 8(17 \cdot 2) \\
39 \cdot 8(22 \cdot 3) \\
37 \cdot 5(20 \cdot 9) \\
77 \cdot 7(24 \cdot 9)\end{array}$ & $\begin{array}{l}77 \cdot 3(19 \cdot 5) \\
69 \cdot 9(39 \cdot 6) \\
68 \cdot 9(39 \cdot 6) \\
77 \cdot 5(23 \cdot 9) \\
68 \cdot 1(22 \cdot 3) \\
57 \cdot 0(22 \cdot 8) \\
53 \cdot 1(23 \cdot 4) \\
56 \cdot 7(27 \cdot 0)\end{array}$ & $\begin{array}{l}0.001 \\
0.005 \\
\text { NS } \\
0.025 \\
\text { NS } \\
0.001 \\
0.001 \\
0.001\end{array}$ \\
\hline
\end{tabular}

Values are means (SD) moderately or very satisfied with the amount of time they spent with clinical staff.

CLINICAL STATUS AND QUALITY OF LIFE

There were substantial correlations between symptom patterns and quality of life and emotional wellbeing. Table 4 summarises scores on the SF-36 scales in patients with and without dyspnoea. After adjusting for age, significant differences were recorded for all subscales except role limitations owing to emotional factors and mental wellbeing $(P<0.025)$. In each case, patients with dyspnoea reported poorer quality of life. Differences on the Hospital Anxiety and Depression scales were not significant. Quality of life was also associated with patterns of chest pain (table 5), with poorer function on all scales except for mental wellbeing among patients with chest pain. Differences among the various types of chest pain were not consistent, although patients who experienced both atypical and exertional pain had the lowest scores on physical functioning, role limitations owing to physical factors, general health perceptions, vitality, and bodily pain. There were no differences in anxiety on the Hospital Anxiety and Depression scales, but the difference in depression was significant $(P<0.025)$. Depression averaged 4.11 (3.2) in patients without chest pain, 5.00 (3.1) in those with atypical pain, 6.05 (3.4) in patients with exertional pain, and $7.5(4.4)$ in patients with both atypical and exertional pain.

Patients who experienced syncope or presyncopal symptoms had significantly lower scores on the SF-36 physical functioning and bodily pain scales $(\mathrm{P}<0.025)$ than those without. Similarly, percentage predicted $\mathrm{VO}_{2} \max$ was positively correlated with physical functioning $(r=0.23, \mathrm{P}<0.01)$ and bodily pain $(r=0.32, \mathrm{P}<0.001)$, after controlling for age. Maximum left ventricular wall thickness was not associated with quality of life measures in male patients. However, among women, left ventricular wall thickness was negatively correlated with role limitations owing to physical problems $(r=-0.29$, $P<0.05)$ and with bodily pain $(r=-0.31$, $P<0.05)$, with poorer function in patients with greater hypertrophy. Time since hypertrophic cardiomyopathy was first diagnosed was not related to quality of life or psychological wellbeing.

\section{FACTORS ASSOCIATED WITH GOOD QUALITY OF} LIFE

Multiple regression analyses were performed to assess which factors were independently

Table 5 Quality of life and chest pain

\begin{tabular}{|c|c|c|c|c|c|}
\hline & No chest pain & Atypical pain & Exertional pain & $\begin{array}{l}\text { Atypical }+ \\
\text { exertional pain }\end{array}$ & $P^{\star}$ \\
\hline $\begin{array}{l}\text { Physical functioning } \\
\text { Physical role limitations } \\
\text { Emotional role limitations } \\
\text { Social functioning } \\
\text { Mental wellbeing } \\
\text { General health perceptions } \\
\text { Vitality } \\
\text { Bodily pain }\end{array}$ & $\begin{array}{l}74 \cdot 4(19 \cdot 8) \\
74 \cdot 6(36 \cdot 1) \\
78 \cdot 1(32 \cdot 6) \\
79 \cdot 3(23 \cdot 1) \\
69 \cdot 1(21 \cdot 1) \\
55 \cdot 5(22 \cdot 5) \\
52 \cdot 7(22 \cdot 4) \\
77 \cdot 5(22 \cdot 8)\end{array}$ & $\begin{array}{l}57 \cdot 0(22 \cdot 6) \\
38 \cdot 3(41 \cdot 0) \\
46 \cdot 6(43 \cdot 3) \\
63 \cdot 3(20 \cdot 3) \\
67 \cdot 2(21 \cdot 2) \\
42.9(28 \cdot 2) \\
44 \cdot 0(19 \cdot 7) \\
60 \cdot 2(27 \cdot 7)\end{array}$ & $\begin{array}{l}49 \cdot 8(23 \cdot 1) \\
40 \cdot 5(42 \cdot 2) \\
47 \cdot 6(46 \cdot 6) \\
64 \cdot 2(25 \cdot 1) \\
63 \cdot 4(18 \cdot 6) \\
42 \cdot 4(23 \cdot 1) \\
37 \cdot 0(24 \cdot 0) \\
59 \cdot 0(27 \cdot 5)\end{array}$ & $\begin{array}{l}42.0(29 \cdot 7) \\
35.0(42 \cdot 8) \\
63.3(42.9) \\
62.5(27 \cdot 6) \\
65.6(16.0) \\
34.5(24 \cdot 7) \\
29.0(23 \cdot 4) \\
41.0(30.7)\end{array}$ & $\begin{array}{l}0.001 \\
0.001 \\
0.005 \\
0.01 \\
\text { NS } \\
0.01 \\
0.005 \\
0.001\end{array}$ \\
\hline
\end{tabular}

Values are means (SD). ${ }^{\star}$ Comparing chest pain $v$ no chest pain. 
associated with deterioration in quality of life measures. So as to reduce the number of analyses performed (and to protect against type 1 error) three target outcomes were selected: role limitations owing to physical factors (SF-36), social functioning (SF-36), and depression (Hospital Anxiety and Depression scale). The factors included as possible predictors were age, sex, time since diagnosis, maximum left ventricular wall thickness, $\mathrm{VO}_{2} \max$, chest pain, dyspnoea, the presence of syncope, social support, and adjustment and patient satisfaction measures.

Role limitations owing to physical factors was predicted by four variables that together accounted for $31.1 \%$ of the variance. Fewer role limitations were associated with good adjustment to hypertrophic cardiomyopathy $(P<0.01)$, younger age $(P<0.01)$, the absence of chest pain $(P<0.01)$, and a higher $\mathrm{VO}_{2} \max (P<0.05)$. Only two variables were independently associated with social functioning, namely good adjustment to hypertrophic cardiomyopathy $(\mathrm{P}<0.005)$, and higher $\mathrm{VO}_{2}$ $\max (P<0.05)$. These indices together accounted for $18.5 \%$ of the variance in social functioning. Finally, low depression on the Hospital Anxiety and Depression scale was independently associated with the absence of chest pain $(P<0.05)$, satisfaction with time spent in the clinic $(P<0.01)$, and satisfaction with communication in the clinic $(P<0.05)$. These factors in combination accounted for $24.3 \%$ of the variance in depression.

\section{Discussion}

The major aim of this study was to evaluate the impact of hypertrophic cardiomyopathy on health related quality of life and emotional wellbeing. The use of the SF-36 permitted comparisons to be made with published information from other patient groups, as this measure has been employed with a wide range of problems including hypertension, arthritis, Parkinson's disease, and stroke. ${ }^{1213}$ The Hospital Anxiety and Depression scale has also been used extensively with many conditions, including coronary artery disease, ${ }^{14}$ breast cancer, ${ }^{15}$ and bronchial asthma. ${ }^{16}$ The response rate was satisfactory $(80 \%)$, and no differences in demographic characteristics were found between responders and nonresponders.

The analysis of the SF-36 indicated marked limitations in many aspects of the quality of life of patients with hypertrophic cardiomyopathy. Poor quality of life was recorded not only in terms of physical functions, perceptions of health and pain, but also in relation to social and emotional functioning. An interesting contrast emerged with the severely ill cardiac patients included in the Medical Outcomes Study. ${ }^{10}$ Cardiomyopathy patients were comparable to this group in terms of impairments in physical functioning, vitality, general perceptions of health, and bodily pain. However, they showed poorer quality of life in other dimensions including mental wellbeing, social functioning, and limitation in roles owing to emotional problems. This suggests that hypertrophic cardiomyopathy is associated with a global deterioration in health related quality of life.

Analysis of the Hospital Anxiety and Depression scale suggested raised levels of anxiety in particular, with $49.7 \%$ of patients showing possible or probable anxiety problems. This high prevalence is a cause for concern; however, it is not unusual for cardiac patients. A recent study of patients with coronary artery disease recruited from St George's Hospital showed that $26 \%$ had possible and $21 \%$ probable anxiety problems, while $14 \%$ had possible and $3 \%$ probable depressive disorders. ${ }^{17}$ Similar or even higher prevalence of psychological problems have been reported by others. ${ }^{14} 18$

Quality of life was strongly associated with symptom patterns in this study, with chest pain and dyspnoea being particularly important. It is clear that the scores on most quality of life scales were much closer to population norms in patients who did not experience these symptoms (tables 4 and 5). Chest pain was also an independent predictor of both role limitations owing to physical factors and depression in multiple regression analyses. In contrast, the clinical cardiac measures included in this study were not consistent predictors of quality of life in multivariate analysis. This corroborates findings with other cardiac conditions in which objective physical and clinical indices are inconsistently associated with social and psychological adjustment. ${ }^{19} 20$

The measure of adjustment to hypertrophic cardiomyopathy emerged as an important factor. One third of patients were categorised as having good adjustment, based on agreeing or strongly agreeing with all five statements in this measure. Adjustment to cardiomyopathy was the most consistent correlate of the dimensions of quality of life and psychological wellbeing, independent of demographic and clinical variables. It might be argued that poor adjustment is merely one aspect of limited quality of life. However, it is significant that this specific measure of how people come to terms with their health problems was predictive of a range of difficulties across the physical, social, and emotional spectrum. The adaptation scale may prove useful in identifying patients who are at high risk of problems of living.

The sample of hypertrophic cardiomyopathy patients was divided on the basis of family history into three groups, as we anticipated that quality of life might differ across these groups. In particular, patients with a sudden death in the family had direct experience of the consequences of the condition that might have led to increased distress. However, there were no differences in psychological wellbeing or quality of life as a function of family history. The other two groups of patients had their own difficulties, such as coming to terms with a new potentially life threatening diagnosis, and having restrictions placed on everyday activities; these factors may have lead to equally 
adverse effects on adaptation and quality of life. The one topic on which differences between groups were observed was satisfaction with information provided in the clinic. The clinical team at St George's Hospital places considerable emphasis on supporting patients with cardiomyopathy. Efforts are made to explain the condition and its implications for personal and family health, to advise patients about prudent lifestyle changes, and to reassure them that the outlook is favourable. These efforts are reflected in the high levels of patient satisfaction reported in this survey. More than $90 \%$ of patients were highly satisfied with the relationships they had established with clinical staff. It is also notable that depression ratings were lower among patients who were more satisfied with clinical contact. Nevertheless, worry about cardiomyopathy remained a widespread problem (table 3 ), and possibly one that is inherent in the condition. For despite reassurance and education, uncertainties about prognosis inevitably persist. The tragic consequences of the illness are especially tangible for patients with a family history of cardiomyopathy and sudden death, and this may render them less satisfied with the information available from clinicians.

This survey was cross sectional and involved patients who had been diagnosed with hypertrophic cardiomyopathy for many years on average. Longitudinal studies are required to determine how limitations in quality of life evolve. Patients were studied at a tertiary centre so may not be representative of people with this condition. The results suggest that despite the thorough evaluation and counselling efforts made in a specialist clinic, poor quality of life is widespread. The problems confronted by patients with hypertrophic cardiomyopathy are poorly understood by non-specialist clinicians and by the general public, as the condition has few obvious signs and many patients appear healthy. Because information about the disease is limited, misconceptions persist and may add to the difficulties of adaptation among patients. Greater public and medical education would therefore be beneficial.

1 McKenna WJ. Hypertrophic cardiomyopathy. In: Julian DG, Camm AJ, Fox KM, Hall RJC, Poole-Wilson PA, eds. Diseases of the heart. 2nd edn. London: WB Saunders, 1996:506-17.

2 WHO/IFSC. Report of the WHO/IFSC task force on the definition and classification of cardiomyopathies. $\mathrm{Br}$ Heart $\mathcal{1}$ 1980;44:672-3.

3 Ware JE Jr, Sherbourne CD. The MOS 36-item short-form health survey (SF-36). I. Conceptual framework and item selection. Med Care 1992;30:473-83.

4 Jenkinson C, Wright L, Coulter A. Short Form 36 (SF 36) Health Survey Questionnaire: normative data for adults of working age. BMF 1993;306:1437-40.

5 Zigmond S, Snaith R. The Hospital Anxiety and Depression Scale. Acta Psychiatr Scand 1983;86:1-7.

6 Berrenberg JL. The Cancer Attitude Inventory: development and validation. $\mathcal{F}$ Psychosoc Oncol 1991;9:35-44.

7 Shapiro LM, McKenna WJ. Distribution of left ventricular hypertrophy in hypertrophic cardiomyopathy: a two hypertrophy in hypertrophic cardiomyopathy: a two
dimensional echocardiographic study. $\mathscr{f} \mathrm{Am}$ Coll Cardiol dimensional ech

8 Frenneaux MP, Porter A, Caforio ALP, Odawara H, Counihan PJ, McKenna WJ. Determinants of exercise capacity in hypertrophic cardiomyopathy. $\mathcal{f} \mathrm{Am}$ Coll Cardiol 1989;13:1521-6.

9 Jenkinson C, Layte $\mathrm{R}$, Wright L, Coulter A. The U.K. SF36: an analysis and interpretation manual. Oxford: Health Services Research Unit, 1996.

10 McHorney CA, Ware JE Jr, Raczek AE. The MOS 36-Item Short-Form Health Survey (SF-36): II. Psychometric and clinical tests of validity in measuring physical and mental health constructs. Med Care 1993;31:247-63.

11 Moorey S, Greer S, Watson M, Gorman C, Rowden L, Tunmore $\mathrm{R}$, et al. The factor structure and factor stability of the Hospital Anxiety and Depression Scale in patients
with cancer. Br $\mathcal{F}$ Psychiatr 1991;158:255-9.

12 Lyons RA, Lo SV, Littlepage B. Comparative health status of patients with 11 common illnesses in Wales. I

13 Jenkinson C, Peto V, Fitzpatrick R, Greenhall R, Hyman N. Self-reported functioning and well being in patients with Parkinson's Disease: comparison of the Short Form Health Survey (SF-36) and the Parkinson's Diseas Questionnaire (PDQ-39). Age Aging 1995;24:505-9.

14 Lewin B, Robertson IH, Cay EL, Irving JB, Campbell M. Effects of self-help post-myocardial-infarction rehabilitation on psychological adjustment and use of health services. Lancet 1992;339:1036-40

15 McArdle JM, George WD, McArdle CS, Smith DC, Moodie AR, Hughson AV, et al. Psychological support for patients undergoing breast cancer surgery: a randomised study. BMF 1996;312:813-16.

16 Bosley CM, Fosbury JA, Cochrane GM. The psychological factors associated with poor compliance with treatment in asthma. Eur Respir $₹$ 1995;8:899-904.

17 Trzcieniecka-Green A, Steptoe A. The effects of stress management on the quality of life of patients following management on the quality of life of patients following Eur Heart $\mathcal{f} 1996 ; 17: 1663-70$.

18 Underwood MJ, Firmin RK, Jehu D. Aspects of psychological and social morbidity in patients awaiting coronary artery bypass grafting. $\mathrm{Br}$ Heart $\mathcal{F} 1993 ; 69: 382-4$.

19 Mayou $R$. Prediction of emotional and social outcome after a heart attack. $\mathcal{F}$ Psychosom Res 1984;28:17-26.

20 Mayou R, Bryant B. Quality of life after coronary artery surgery. Quart f Med 1987;62:239-48. 